\title{
HISTOPATHOLOGICAL STUDY OF ENDOMETRIUM IN INFERTILITY
}

\author{
Gireesh Vishnupant Achalkar ${ }^{1}$
}

${ }^{1}$ Associate Professor, Department of Pathology, Raichur Institute of Medical Sciences, Raichur, Karnataka, India.

\section{BACKGROUND}

\section{ABSTRACT}

Infertility is a medical as well as social problem. This causes severe mental stress in infertile couples, especially in women. The parenthood is the natural way of life. In ordinary course of life, couples usually have children in majority of cases. The incidence of infertility varies from region to region.

Aims and Objectives- To find out the incidence of various endometrial pathologies in cases of infertility.

\section{MATERIALS AND METHODS}

A descriptive study was carried out in the Department of Pathology, RIMS, Raichur. 200 cases of primary and secondary infertility were studied. Endometrial biopsies were evaluated with available menstrual history. Premenstrual phase endometrial biopsies were obtained. Haematoxylin and eosin staining was done for dating of endometrium and diagnosis of luteal phase defect and anovulatory cycles. PAS staining was also done. Proportions and percentages of primary and secondary infertility having various pathology were calculated.

\section{RESULTS}

Menstrual problems were seen in $38 \%$ of patients. Anovulatory infertility was present in $41.73 \%$ cases. Luteal phase defect was seen in $20 \%$ cases. Simple hyperplasia without atypia was seen in $8.4 \%$ cases and tuberculous endometritis was present in $10.7 \%$ cases. Glycogen deficiency was seen in $28.13 \%$ of cases of luteal phase defect.

\section{CONCLUSION}

In the present study of 200 cases, majority were primary infertility cases. Common age group affected was 26 - 30 years. Anovulatory cycles accounted for significant numbers of cases.

\section{KEY WORDS}

Infertility; Endometrium, Hyperplastic, Tuberculous.

HOW TO CITE THIS ARTICLE: Achalkar GV. Histopathological study of endometrium in infertility. J. Evolution Med. Dent. Sci. 2018;7(24):2870-2873, DOI: $10.14260 /$ jemds/2018/647

\section{BACKGROUND}

Infertility is a medical as well as social problem. This causes severe mental stress in infertile couple, especially in women. The parenthood is the natural way of life. In ordinary course of life, couples usually have the child in majority of cases. The incidence of infertility varies from region to region. Approximately, one marriage in ten is barren. ${ }^{1}$

In India, there are about 10.2 million couples of infertility. ${ }^{2}$ There is a stigma in India of being infertile and it has negative implications in routine life. Infertility causes include both men and women almost equally.

About one-third of cases are due to male factor, one-third due to female factor and the remaining one-third unexplained where both of them are responsible and advanced medical techniques may help them in achieving pregnancy.

The purpose of investigating the infertile couple is to know their chance of achieving pregnancy and to identify the important causative factors amenable to treatment. In spite of many investigatory tools available,

'Financial or Other Competing Interest': None.

Submission 30-03-2018, Peer Review 24-05-2018,

Acceptance 31-05-2018, Published 11-06-2018.

Corresponding Author:

Dr. Gireesh Vishnupant Achalkar,

Associate Professor,

Department of Pathology,

Raichur Institute of Medical Sciences,

Raichur, Karnataka, India.

E-mail: drgireesha@yahoo.com

DOI: $10.14260 /$ jemds $/ 2018 / 647$ endometrial histology is a sensitive and gold standard indicator of endometrial and ovarian function.

Premenstrual endometrial biopsy plays an important diagnostic role in cases of infertility. Infertility is defined as no conception after 12 months of unprotected sexual intercourse. It is further classified as primary in which no evidence of conception has occurred and as secondary in which prior conception has occurred, not necessarily a live birth.

Sterility is the extreme case, where there is intrinsic inability in achieving pregnancy. Proper investigation must be started as soon as they seek medical attention. Age is one of the important factor with regard to fecundability, hence investigation must be started at the earliest. ${ }^{2}$ Hence, the importance of detailed pathological study.

\section{Objective}

To find out the incidence of various endometrial pathologies in cases of infertility.

\section{MATERIALS AND METHODS}

It is a descriptive study. The present study was carried out in Department of Pathology, RIMS, Raichur. Endometrial biopsies of 200 cases of primary and secondary infertility were received in Department of Pathology from Department of OBG, during the period from June 2015 to June 2017.

Detailed clinical history was taken with special emphasis on monthly periods, any chronic illness and married life. Past medical and obstetric history was noted. Any radiological and ultrasonographic findings were noted. Premenstrual 
endometrial biopsy specimens were obtained. Tissue was fixed in formalin and processed.

Paraffin blocks were made. 4 - 5 micron thick sections were cut and stained with Haematoxylin and Eosin. The sections were studied with regard to dating of endometrium and other pathologies. Haematoxylin and eosin stained sections were studied to date the endometrium accurately based on the criteria described by Dallenbach Hellweg. ${ }^{3}$

Periodic acid-Schiff (PAS) staining was done in all 200 cases and 25 normal controls. This stain is used primarily to detect the amount of glycogen in the cytoplasm. The findings were studied and analysed to find out the incidence of various changes with regard to glycogen content in the cytoplasm in the endometrium glands. ${ }^{4}$

The proportions and percentages of primary and secondary infertility of various pathologies were calculated.

\section{RESULTS}

Amongst 200 cases of infertility 173 cases (86.5\%) were of primary infertility, $27(13.5 \%)$ cases were of secondary infertility.

The maximum numbers of patients were in the age range of 19 - 36 years. The youngest patient was 18 years old and the oldest was 42 years. In primary infertility group majority came to seek medical help within 2 - 3 years, whereas patients with secondary infertility sought medical help after 6-7 years after last conception.

Menstrual problems were seen in $35(22.62 \%)$ cases of primary infertility and $33(23.08 \%)$ cases of secondary infertility. Irregular menses were seen in 54 (37.84\%) cases of primary infertility and $21(38.46 \%)$ cases of secondary infertility.

200 endometrial specimens were analysed for the various changes in endometria (Table 1). The various morphological patterns of endometrium were studied. Of the total of 200 cases were studied. $173(86.5 \%)$ cases belonged to primary infertility and $27(13.5 \%)$ to secondary infertility. Majority were primary infertility cases.

\begin{tabular}{|c|c|c|}
\hline Type of Infertility & Number & Percentages (\%) \\
\hline Primary & 173 & 86.5 \\
\hline Secondary & 27 & 13.5 \\
\hline Total & $\mathbf{2 0 0}$ & $\mathbf{1 0 0}$ \\
\hline Table 1. Incidence of Primary and Secondary Infertility \\
\hline
\end{tabular}

Age distribution is given in the table below. The youngest patient was 19 years old and the eldest was 42 years old.

\begin{tabular}{|c|c|c|c|c|}
\hline Age Group & $\begin{array}{c}\text { Primary } \\
\text { Infertility }\end{array}$ & $\mathbf{\%}$ & $\begin{array}{c}\text { Secondary } \\
\text { Infertility }\end{array}$ & $\mathbf{\%}$ \\
\hline $21-25$ & 28 & 16.1 & - & \\
\hline $26-30$ & 81 & 46.8 & 3 & 11.1 \\
\hline $31-35$ & 52 & 26.1 & 13 & 48.1 \\
\hline $36-40$ & 12 & 6.9 & 10 & 40.7 \\
\hline $41-45$ & 1 & 0,5 & 1 & 0.5 \\
\hline \multicolumn{5}{|c|}{ Table 2. Age Distribution in Infertility } \\
\hline
\end{tabular}

The microscopic features of endometrial biopsies were studied, and the results are as follows (Table 3).

\begin{tabular}{|c|c|c|c|c|}
\hline $\begin{array}{c}\text { Histological } \\
\text { Diagnosis }\end{array}$ & $\begin{array}{c}\text { Primary } \\
\text { Infertility No. } \\
\text { of Cases 173 }\end{array}$ & $\%$ & $\begin{array}{c}\text { Secondary } \\
\text { Infertility No. } \\
\text { of Cases 27 }\end{array}$ & $\%$ \\
\hline $\begin{array}{c}\text { Normal } \\
\text { secretory } \\
\text { endometrium }\end{array}$ & 68 & 39.16 & 20 & 74.23 \\
\hline $\begin{array}{c}\text { Non-secretory } \\
\text { endometrium }\end{array}$ & 72 & 41.73 & 2 & 7.08 \\
\hline $\begin{array}{c}\text { Simple } \\
\text { hyperplasia }\end{array}$ & 15 & 8.40 & 4 & 14.69 \\
\hline $\begin{array}{c}\text { Tuberculous } \\
\text { endometritis }\end{array}$ & 18 & 10.70 & $1-$ & 3.7 \\
\hline \multicolumn{7}{|r|}{ Table 3. Incidence of Changes in Endometria } \\
\hline
\end{tabular}

Anovulatory endometrium was seen in 72 (41.73\%) cases of primary infertility and $2(7.08 \%)$ cases of secondary infertility. 18 cases of primary infertility showed endometrial tuberculosis. However, ZN staining for AFB was negative in all cases (Table 4).

\begin{tabular}{|c|c|c|c|c|c|c|}
\hline Glycogen Content Grade (PAS Staining) & Proliferative Phase Cases & Secretory Phase Cases & \multicolumn{2}{c|}{ Luteal Phase Defect Cases } \\
\hline & Primary & Secondary & Primary & Secondary & Primary & Secondary \\
\hline & 40 & 3 & - & - & - & - \\
\hline & - & - & - & - & 3 & 1 \\
\hline+ & - & - & 4 & 3 & 4 & 1 \\
\hline++ & - & - & 24 & 6 & - & - \\
\hline+++ & - & - & 32 & 6 & - & - \\
\hline++++ & 40 & 3 & 60 & 15 & 7 & 2 \\
\hline Total & Table 4. Histology and
\end{tabular}

\section{The Glycogen Content was graded as Follow Arzac and Blanchet}

- $\quad$ Negative reaction.

- $\quad+$ - Very small granules.

- $\quad++-$ Coarse granules.

- $\quad+++$ - Small masses.

\section{DISCUSSION}

The studies of populations of patients with infertility indicate that approximately $10 \%-25 \%$ have unexplained infertility, $20 \%-30 \%$ have ovulatory dysfunction. $20 \%-30 \%$ have tubal damage; $12 \%$ - $50 \%$ sperm dysfunction. $6 \%$ to $10 \%$ endometriosis; $5 \%$ cervical mucus problems and $3 \%$ to $5 \%$ coital dysfunction. ${ }^{1}$ The most important prognostic factors are duration of infertility and the age of the female partner.

The fertility investigation should be instigated as soon as the couples seek help, even if they have been trying for less than a year. General questions should be asked such as irregularities of menstrual cycle, pelvic surgery or orchidopexy.

Determining the cause of anovulatory infertility is the key to treatment, as the correction of the cause will result in cumulative conception rates that mimic those expected for 
normal women of the same age. It must be ascertained whether ovulation is occurring. ${ }^{2}$

The present study of 200 cases of infertility included 173 of primary and 27 of secondary causes. Majority were primary infertility cases. The reason may be the patients with secondary causes do not get investigated for the second child.

Human endometrium is important site for nidation of fertilised ovum. ${ }^{5}$ The present study was done to systematically evaluate the adequacy of endometrial development based on correlating menstrual history, date with glandular and stromal morphological features and pathological findings.

Properly developed follicles and corpus luteum formation is very much essential for the continuation of normal pregnancy. Initially, the hormone progesterone is synthesised and secreted by corpus luteum. Later this work is taken over by the placenta. 6 The normal physiologically balanced hormonal profile is needed for the uninterrupted progress of pregnancy.

The diagnosis of luteal phase defect was made by using Jones criteria. ${ }^{7,8}$ For this, the histological findings with regard to dating of endometrium were studied. This was compared with date of menstrual cycle as given by the patient. A difference of more than two days defines the luteal phase defect.9,10

The non-secretory endometrium was an important pathological finding in $\mathrm{H}$ and $\mathrm{E}$ sections and it constituted the most common cause for infertility. The other important cause was luteal phase defects (Table 5). This observation is comparable with that of other authors.

\begin{tabular}{|c|c|c|}
\hline Studies & $\begin{array}{c}\text { \% of Non-Secretory } \\
\text { Endometrium }\end{array}$ & $\begin{array}{c}\text { \% of Secretory } \\
\text { Endometrium }\end{array}$ \\
\hline Shetty (1959) ${ }^{[8]}$ & 15.2 & $74.8 \%$ \\
\hline Gupta et al (1980) $[9]^{[9]}$ & 22.8 & $68.5 \%$ \\
\hline Sareen (1984) ${ }^{[10]}$ & 19 & $79 \%$ \\
\hline $\begin{array}{c}\text { Jadhav and Raichur } \\
(1987)^{[11]}\end{array}$ & 25 & $75 \%$ \\
\hline Sabharwal (1987) ${ }^{[12]}$ & 12 & $84 \%$ \\
\hline $\begin{array}{c}\text { Krishnamohan et al } \\
(1993)^{[13]}\end{array}$ & $10 \%$ & $87.5 \%$ \\
\hline $\begin{array}{c}\text { Neil Shastrabudhe } \\
(2001)^{[14]}\end{array}$ & $34.2 \%$ & $62.3 \%$ \\
\hline Present Study (2002) & $41.73 \%$ & $39.16 \%$ \\
\hline $\begin{array}{c}\text { Table 5. Histopathological Abnormalities in the Form of } \\
\text { Anovulatory Endometrium and Luteal Phase Defect }\end{array}$ \\
\hline
\end{tabular}

Anovulatory cycles with non-secretory endometrium are common pathological observations in cases of primary as well as secondary infertility. ${ }^{11,12}$ Our present study showed anovulatory endometrium in $41.73 \%$ cases.

Secretory phase endometrium is diagnosed by the histological features of subnuclear vacuolations and intraluminal secretions. The observation and recognition of this feature is one of the most important part of the accurate reporting by the pathologist. This gives information with regard to ovulation.

Luteal phase defect may be the cause of infertility in ovulatory cycles.13,14 Twenty-one cases were included in this category. This was compared with the observations made by other authors. The cause for luteal phase defect is hormonal, mostly due to deficiency of progesterone and some are due to raised TSH. These patients respond to the hormonal treatment accordingly.

Tuberculous endometritis ${ }^{15}$ and simple hyperplasia without atypia formed a minor cause of infertility in present study. The present study shows incidence of tuberculous endometritis in more number of cases compared to other studies. The reason may be India having increased number of tuberculosis patients. ${ }^{16}$

It takes minimum of 2 weeks for the granuloma to form. It might shed with the endometrium and hence may not be available in the biopsy specimen. Rani PR found that in patients of genital tuberculosis, ${ }^{17}$ the most common site of involvement is endometrium in $46.6 \%$ cases.

Manjiri ${ }^{18}$ and Kumar A, ${ }^{19}$ Nagpal $\mathrm{M}^{20}$ found endometrial tuberculosis as compared with present study and that of Andita B and Tripathy21 (Table 6).

\begin{tabular}{|c|c|}
\hline Author and Year & $\%$ of Tuberculous Endometritis \\
\hline Zawar et al & $2.6 \%$ \\
\hline Sathe et al & $6 \%$ \\
\hline Schaefer & $5.1 \%$ \\
\hline Gupta et al[22] & $8.7 \%$ \\
\hline Sareen[10] & $2 \%$ \\
\hline Sabharwal[12] & $1.34 \%$ \\
\hline P. Chakroborty & $6.2 \%$ \\
\hline R. Mishra & $4.9 \%$ \\
\hline Shastrabudhe N[14] & $2.6 \%$ \\
\hline Present Study & $10.7 \%$ \\
\hline
\end{tabular}

The endometrial hyperplasia due to excess level of oestrogen can also prevent pregnancy. ${ }^{24,25}$ In present study, simple hyperplasia without atypia was seen in $8.4 \%$ of cases (Table 7).

\begin{tabular}{|c|c|}
\hline Author and Year & Glycogen Deficiency in \% \\
\hline Zondek and Stein & $18.4 \%$ \\
\hline Shetty ${ }^{[8]}$ & $44.6 \%$ \\
\hline Zawar et al & $30 \%$ \\
\hline Anshu et al & $24.7 \%$ \\
\hline Rohtangi & $22.5 \%$ \\
\hline Sareen[10] & $39 \%$ \\
\hline S. Sharma[23] & $28.5 \%$ \\
\hline Present Study & $28.13 \%$ \\
\hline \multicolumn{2}{|c|}{$\begin{array}{c}\text { Table 7. Glycogen Deficiency as a cause of Infertility } \\
\text { observed by Various Authors }\end{array}$} \\
\hline
\end{tabular}

In present study, PAS stain was done in 200 cases of infertility to assess the amount of glycogen content. It is necessary for the successful conception and subsequent growth and development of fertilised ovum in the uterus.

It is very much necessary that adequate amount of carbohydrate in general and glycogen in particular must be present in the glandular secretions. The glycogen is a major source of glucose and energy to the developing embryo. ${ }^{24,25}$

\section{CONCLUSION}

In the present study of 200 cases, majority were primary infertility cases. Common age group affected was 26 - 30 years. Anovulatory cycles accounted for significant numbers of cases. 
Histopathological study of endometrium is an important, safe and cheaper diagnostic tool in cases of primary and secondary infertility. It gives immense significant information with regard to structure, function and any pathological lesions in endometrium. The secretory endometrium and adequate carbohydrate content in the cytoplasm of endometrial glandular cells is an essential prerequisite for successful implantation and development of embryo.

\section{REFERENCES}

[1] Kleegman SJ, Kaufmann SA. Infertility in women. $1^{\text {st }}$ edn. Philadelphia, USA: FA Davis Company Publisher 1966: p. 178.

[2] Dawn CS. Textbook of Gynaecology. $5^{\text {th }}$ edn. Calcutta, India: Dawn Books 1976.

[3] Dallenbach H. Histopathology of Endometrium. 4th edn. Berlin: Springer Verlag 1980.

[4] Arzac JP, Blanchet E. Alkaline phosphatase and glycogen in human endometrium. J Clin Endocrinol Metab 1948;8(4):315-24.

[5] Majhi AK. Luteal phase defect: still a mystery in female infertility. Obstet Gynaecol Today 2002.

[6] Jones GS. The luteal phase defect. Fertil Steril 1976;27(4):351-6.

[7] Gupta AN, Vashishtak AS. Study of endometrium in infertile women. J Obstet Gynaecol India 1980;8:27-32.

[8] Jadhav MV, Raichur BS. Special stains in study of normal and abnormal endometrium. Indian J Pathol Microbiol 1987;30(3):307-11.

[9] Shastrabudhe NS, Shinde S, Jadhav MV. Endometrium in infertile women. Ind J Obstet Gynaecol 2001;51:100-2.

[10] Wentz AC, Kossoy LR, Parker RA. The impact of luteal phase inadequacy in an infertile population. Am J Obstet Gynecol 1990;162(4):937-43.
[11] Soules MR. Luteal phase deficiency. An under diagnosed and overtreated reproductive endocrine disorder. Obstet Gynecol Clin North Am 1987;14(4):865-86.

[12] Mridu M, Khanna S, Kahlon SK. Genital Tuberculosis. Asian J Obstet 1993.

[13] Kumar A, Gupta N. Genitaln Tuberculosis. Asian J Obstet Gynaecol: 2000.

[14] Tripathy SN, Tripathy SN. Infertility and pregnancy outcome in female genital tuberculosis. Int J Gynaecol Obstet 2002;76(2):159-63.

[15] Driessen F, Holwerda PJ, vd Putte SC, et al. The significance of dating an endometrial biopsy for the prognosis of the infertile couple. Int J Fertil 1980;25(2):112-6.

[16] Aikat BK, Pathak IV. Gupta Tuberculosis of Endometrium. J Obstet Gyanecol 1952.

[17] Schaefer G. Pelvic Tuberculosis. Clin Obstet Gynecol 1976.

[18] Zondek B, Shapino A. Endometrial glycogen content in infertiltiy. Am J Obstet 1984.

[19] Sharma SC, Hasan BK. Endometrial glycogen in sterility. J Obstet Gyanecol 1952;2:140-4.

[20] Schaefer G. Female genital tuberculosis. Clin Obstet Gynecol 1976;19(1):223-39.

[21] Baveja R, Verma HC. Endometrial glycogen in infertilrty. Proc All India Obsyet Gyanecol Cong 1972.

[22] Gupta PL, Jethani V. Endometrial glycogen - an important parameter of infertility. J Obstet Gyanecol India 1994.

[23] Sharma SC, Banarjee AK, Hasan BK. Endometrial glycogen in sterlity. J Obstet Gyanecol India 1984.

[24] Sophia J, Kleefman SA. Infertility in women. $1^{\text {st }}$ edn. Philadelphia, USA: FA Davis Company Publisher 1966: p. 165-71. 